\title{
Prognostic value of treadmill exercise echocardiography
}

\author{
Jesús Peteiro-Vázquez, Lorenzo Monserrrat-Iglesias, Javier Mariñas-Davila, Iris P. \\ Garrido-Bravo, María Bouzas-Caamaño, Javier Muñiz-García, Alberto Bouzas- \\ Mosquera, Beatriz Bouzas-Zubeldia, Nemesio Álvarez-García, Alfonso Castro-Beiras
}

\begin{abstract}
Introduction and objectives. Exercise echocardiography (EE) is useful for diagnosing coronary disease, but little is known about its value for risk stratification. We aimed to determine: $a$ ) whether data from EE supplemented clinical data and data from exercise testing and resting echocardiography in predicting cardiac events; and $b$ ) whether the number and location of abnormal regions and their responses to exercise influenced risk stratification.

Patients and method. The 2,436 patients referred for EE were followed up for $2.1 \pm 1.5$ years. Some 120 serious cardiovascular events (i.e., non-fatal myocardial infarction or cardiovascular death) occurred before revascularization. Results. In 1203 patients (49\%), EE gave abnormal results. There were 89 events in patients with an abnormal result $(7.3 \%)$ and 31 in those with a normal result $(2.5 \% ; P<.0001)$. Multivariate analysis of clinical data, and data from exercise testing, resting echocardiography, and EE showed that male sex (RR=1.7; 95\% CI, 1.1-2.8; $P=.02$ ), metabolic equivalents or METs $(\mathrm{RR}=0.9 ; 95 \% \mathrm{CI}, 0.86-0.98 ; \mathrm{P}=.01)$, peak heart rate $\times$ blood pressure $(\mathrm{RR}=0.9$; $95 \% \mathrm{CI}, 0.9 ; \mathrm{P}=.002)$, resting wall motion score index $(\mathrm{RR}=2.5 ; 95 \% \mathrm{CI}, 1.5-4.1 ; P<.0001)$, and number of abnormal regions at peak exercise $(\mathrm{RR}=1.4 ; 95 \% \mathrm{CI}, 1.2-1.7 ; \mathrm{P}<.0001)$ were independently associated with the risk of a serious event (final model $\chi^{2}, 170$; incremental $P<.0001$ ). The same variables, excluding sex, were independently associated with cardiovascular death (final model $\chi^{2}, 169$; incremental $P=.01$ ).

Conclusions. Exercise echocardiography supplements clinical data and data from exercise testing and resting echocardiography in patients with known or suspected coronary artery disease.
\end{abstract}

\begin{abstract}
Resumen
Introducción y objetivos. Aunque la ecocardiografía de ejercicio es útil para el diagnóstico de la enfermedad coronaria, hay menos datos referentes a su valor pronós-tico. El objetivo de este estudio fue esclarecer: $a$ ) si hay un valor incremental de la ecocardiografía en el pico del ejercicio respecto a las variables clínicas, la prueba de esfuerzo y la ecocardiografía en reposo, y $b$ ) si el número y la localización de los territorios afectados, así como el tipo de respuesta al ejercicio, influyen en la estratificación.

Pacientes y método. En 2.436 pacientes referidos para ecocardiografía de ejercicio se realizó un seguimien-to de 2,1 $\pm 1,5$ años. Hubo 120 eventos (infarto no fatal o muerte cardiovascular) antes de la revascularización.

Resultados. La ecocardiografía fue anormal en 1.203 pacientes (49\%). Hubo 89 eventos en pacientes con resul-tado anormal $(7,3 \%)$ frente a 31 con resultado normal $(2,5 \% ; p<0,001)$. Mediante un análisis multivariable de variables clínicas, de la prueba de esfuerzo y de la ecocardiografía en reposo y ejercicio encontramos que las variables asociadas de manera independiente con el riesgo de eventos eran: ser varón (riesgo relativo $[R R]=1,7$; interva-lo de confianza [IC] del 95\%, 1,1-2,8; $\mathrm{p}=0,02)$, los equiva-lentes metabólicos o MET (RR = 0,9; IC del 95\%, 0,9-1,0; $\mathrm{p}=$ $0,01)$, el producto frecuencia cardíaca $\times$ presión arterial $(\mathrm{RR}=0,9$; IC del 95\%, 0,9-1,0; $\mathrm{p}=0,02)$, el índice de motilidad segmentaria basal $(\mathrm{RR}=2,5$; IC del $95 \%, 1,5-4,1 ; \mathrm{p}<0,0001)$ y el número de territorios afectados $(\mathrm{RR}=1,4$; IC del $95 \%, 1,2-1,7 ; p<0,0001)\left(\chi^{2}\right.$ final = 170, valor incremental de la ecocardiografía en el máximo esfuerzo; $p<$ $0,0001)$. Las mismas variables, excepto el sexo, estaban asociadas con la muerte $\left(\chi^{2}\right.$ final $=169$, valor incremental de la ecocardiografía de ejercicio; $\mathrm{p}=0,01$ ).

Conclusiones. La ecocardiografía en el máximo ejercicio incrementa el valor pronóstico de las variables clínicas, la prueba de esfuerzo y la ecocardiografía de reposo.
\end{abstract}

Key words

Exercise echocardiography; Prognostic value; Treadmill

Palabras clave

Ecocardiografía de ejercicio; Valor pronóstico; Cinta rodante 


\section{Introduction}

Exercise echocardiography (EE) has advanced significantly from the diagnostic point of view, and several recent studies (most carried out at the same center) have shown that the extent of resting or exercise- induced ventricular dysfunction is a robust predictor of cardiac death and myocardial infarction. $^{1-10}$

The purpose of this study was to investigate whether the number and location of diseased territories during the exercise peak, as well as the type of response to exercise (ischemia, necrosis or remote ischemia) influenced risk stratification more than clinical, stress test, and resting echocardiography variables in patients with known or suspected coronary artery disease (CAD). We also investigated whether EE supplemented resting echocardiography in patients with a history of acute myocardial infarction (AMI) as recorded in the medical history.

\section{Patients and methods}

\section{Patients}

We studied 2479 patients who had undergone treadmill EE at our institution during a 4.2-year period from December 1997 to March 2002. Patients with significant valve disease $(n=13)$ or with proven hypertrophic or dilated cardiomyopathy $(n=30)$ were excluded, with the final group composed of 2436 patients who were followed until 31 December 2002. The patients' medical history revealed a history of myocardial infarction in 741 patients $(30 \%)$, that was acute in $386(16 \%)$ with elevation of ST segment in 276; of these, 176 had undergone fibrinolysis (7\%) and 38, primary angioplasty (1.5\%). A total of 385 patients had been previously revascularized (16\%), with coronary angioplasty in $199(8 \%)$, surgery in 167 $(7 \%)$, or both in $19(1 \%)$. There was atrial fibrillation in 130 patients $(5 \%)$, complete left bundle branch block or pacemaker rhythm in $218(9 \%)$, and left ventricular hypertrophy according to echocardiographic criteria (wall thickness $\geq 1.1 \mathrm{~cm}$ ) in $1340(55 \%)$. At the time of EE, $24 \%$ of the patients were taking nitrates $8 \%$, calcium antagonists; $4 \%$, beta-blockers; $22 \%$, angiotensin-converting enzyme inhibitors; $9 \%$, diuretics, and $4 \%$, digoxin.

\section{Exercise Echocardiography}

Data on heart rate and blood pressure were obtained and a 12-lead electrocardiogram (ECG) was recorded at rest and at each stage of the exercise protocol. The patients were encouraged to reach peak exercise according to the protocols adjusted to the characteristics of each patient (Bruce 90\%, modified Bruce 7\%, Naugthon 2\%, Bruce for athletes 1\%) until exhaustion or until reaching a specific criterion for termination. The termination criteria were suppression or elevation of $>2 \mathrm{~mm}$ in ST segment, significant arrhythmia, severe hypertension (systolic blood pressure $>240 \mathrm{~mm} \mathrm{Hg}$ or diastolic blood pressure $>110$ $\mathrm{mm} \mathrm{Hg}$ ) and hypotensive response (decrease $\geq 20 \mathrm{mmHg}$ from baseline). The ECG was considered positive in the case of horizontal or downsloping elevation or depression of ST segment $\geq 1 \mathrm{~mm}$ at $80 \mathrm{~ms}$ after the $\mathrm{J}$ point, and nondiagnostic when the baseline ECG was abnormal or the patient was receiving digoxin.

Two-dimensional echocardiography with fundamental or harmonic imaging was performed in the standard apical and parasternal views at baseline, at the exercise peak, ${ }^{11,12}$ and immediately after exercise. Peak EE was done when there were signs or symptoms of exhaustion or some criterion for termination had been reached. All images were acquired on-line and saved to optical disc for subsequent analysis.

\section{Image Analysis}

The images were analyzed using a quad screen format to compare the same views at baseline and exercise peak. The left ventricle was divided into 16 segments, ${ }^{13}$ with each segment assigned to 1 of the 3 coronary arterial territories. ${ }^{14}$ The onset of regional dysfunction (hypokinesia, akinesia, or dyskinesia) or worsening from hypokinesia to akinesia or dyskinesia was considered an ischemic response. The persistence of baseline regional dysfunction affecting at least one segment or worsening from akinesia to dyskinesia was considered necrosis with no ischemia, except in the case of isolated hypokinesia of the posterobasal segment, ${ }^{15}$ and septal hypokinesia in patients with complete left bundle branch block, pacemaker, or recent heart surgery. In these cases, hypokinesia was considered normal. In patients with global ventricular dysfunction of unknown origin, a response of progressive improvement was considered normal and a diagnosis of dilated cardiomyopathy was suggested. ${ }^{16}$ In all other patients, EE positive for 
CAD was defined as ischemia or necrosis in 1 coronary arterial territory. ${ }^{17-19}$ The following types of response were considered for each patient: normal (same or greater thickening and systolic wall motion with exercise), isolated ischemia (normal thickening/systolic motion at baseline and appearance of regional or global dysfunction with exercise), necrosis (persistence of baseline regional dysfunction with exercise or worsening from akinesia to dyskinesia), necrosis with remote ischemia (presence of baseline regional dysfunction and onset of new dysergia in a different territory), and ischemia and necrosis affecting the same territory (presence of baseline regional dysfunction that worsens in the same territory due to worsening from hypokinesia to akinesia or dyskinesia, or greater extension of dysergia but without affecting territories other than the one affected at baseline). Patients were classified according to the number of abnormal territories ( $0,1,2$, or 3 ) during exercise. Regional wall motion (RWM) was calculated at rest and during exercise, scoring normal motion as 1 , hypokinesia as 2 , akinesia as 3 , and dyskinesia as 4 . The resting and exercise ejection fraction (EF) was measured through visual estimation ${ }^{20}$ by an observer. Data are provided for between-observer variability in the visual estimation of EF at our center from an analysis of 60 studies selected at random (20 with fundamental imaging, 40 with harmonic) and assessed on 2 occasions 36 months apart.

\section{Follow-up}

Events were followed up and assessed through a review of the medical histories and death certificates. We had access to hospital admissions, out-of-hospital consultations, and emergency room services of all SERGAS centers; no patients were lost during follow-up. If no data were available for a patient at the end of the study (31 December 2002), the health card database was consulted to determine whether the patient had died or moved to a location outside the autonomous community. In the event of death of unknown origin, precise information on the cause (cardiovascular, neoplasm, etc) was obtained from the Death Register of Galicia. Only hard events were considered, with these defined as death of cardiovascular origin or nonfatal AMI. Sudden death occurring with no other explanation was considered of cardiac origin. Revascularization procedures during follow-up were recorded. Patients who were revascularized before an event were excluded at the time of the event.

\section{Statistical Analysis}

Continuous variables are described as mean \pm standard deviation (SD), with the comparison between patients with and without events based on the Mann-Whitney U-test. Categorical variables are described as percentages and the between-group comparison was done using $\chi^{2}$. Event-free survival was estimated by Kaplan-Meier using time to first event. Patients who died due to noncardiovascular events and those who were revascularized before an event were excluded at the time of death or revascularization.

Univariate associations of clinical variables, ECG, and EE with hard events were measured with the Cox proportional hazards model. Significance was set at a $P$ value of less than .05 and the $95 \%$ confidence intervals (CI) were calculated. The incremental value of EE with respect to clinical and ECG variables was measured step-by-step, considering for entry into each step those variables that were significant in the univariate analysis, in which the first step only included clinical data; the second step consisted of hemodynamic and ECG data in response to exercise; afterwards, the resting echocardiography data were entered; in the final step, the EE variables were included. The $\chi^{2}$ values and the incremental value of adding the subsequent variables were calculated for each step.

Variability in the calculation of visual EF is expressed as the quotient between the difference of the 2 measurements and the mean value of both $\times 100$.

\section{Results}

The mean patient age was $62 \pm 12$ years. There were 1584 men (65\%) and 852 women (35\%). Diabetes mellitus was observed in 449 patients (18\%), hypertension in 1325 (54\%), smoking in $688(28 \%)$, hypercholesterolemia in 1272 (52\%), and family history of CAD in $376(15 \%)$. The reasons for performing EE were precordial pain or dyspnea in 1582 patients (65\%), history of AMI in 725 (30\%), positive or nondiagnostic ECG in $111(5 \%)$, and evaluation of risk factors in $18(0.7 \%)$. The stress test was discontinued because of exhaustion in 2212 patients $(91 \%)$, angina in $63(3 \%)$, lower limb pain in $148(6 \%)$, and arrhythmias in 3 patients $(0.1 \%)$. 


\section{Exercise Echocardiography Data}

The EE was considered normal in 1233 patients (51\%) and abnormal in $1203(49 \%)$. There were baseline alterations in regional motion in 652 patients $(27 \%)$. Among the 1203 patients with an abnormal EE, 282 had only necrosis $(23 \%)$; 547, ischemia $(45 \%) ; 284$, remote ischemia $(24 \%)$, and 90, ischemia and necrosis in the same territory $(7 \%)$. In the patients with normal EE, involvement of 1 territory was found in $566(47 \%), 2$ territories in $230(19 \%)$, and 3 territories in 407 patients (34\%). Among patients with abnormal EE, the EE was positive for disease in the left anterior descending artery territory in 870 (72\%) and positive for disease in the right coronary artery or circumflex artery territory in $913(76 \%)$.

In patients with a history of AMI as recorded in the medical history, EE was normal in $97(13 \%)$ and abnormal in 644 (87\%). Abnormal EE was categorized as necrosis in 30\%, ischemia in $22 \%$, remote ischemia in $24 \%$, and necrosis associated with ischemia in the same territory in $10 \%$. Multi-territory disease was reported in 311 patients $(42 \%)$.

\section{Revascularization Procedures}

A total of 454 patients (20\%) were revascularized during follow-up, 152 surgically and 302 by angioplasty. Of these, 427 patients who were revascularized before a hard event were excluded. The reasons for revascularization were coronary event in 89 patients $(20 \%)$ and EE result in $365(80 \%)$. Early revascularization ( $\leq 3$ months) was done in 279 patients and late revascularization ( $>3$ months) in 175 . In most cases of early revascularization, the reason was the EE result (89\%), whereas late revascularization was carried out because of the EE result in $66 \%$ of the cases and onset of acute coronary syndrome in $34 \%$. The revascularized patients had a higher prevalence of angina during exercise (38\% vs $9 \% ; P$ $<.0001)$, positive ECG (37\% vs $12 \% ; P<.0001)$, abnormal EE (87\% vs $41 \% ; P<.0001)$, ischemia on EE (79\% vs $28 \% ; P<.0001)$, and involvement of more than 1 territory $(56 \%$ vs $19 \% ; P<.05)$.

\section{Events}

Over a mean follow-up of 2.1 \pm 1.5 years (median, 2.0 years; maximum, 5 years) there were 167 cardiovascular events: cardiovascular death in 112 patients and nonfatal AMI in 55. There were significant differences in baseline characteristics between the 2269 patients who had no events during follow-up and the 167 who had some event: age $(61 \pm 11$ vs $64 \pm 10$ years; $P<.001)$, male sex $(64 \%$ vs $81 \% ; P<.001)$, diabetes $(18 \%$ vs $24 \% ; P=.05)$, smoking $(28 \%$ vs $35 \% ; P<.05)$, previous revascularizations $(15 \%$ vs $22 \% ; P=.01)$, precordial pain or dyspnea as reason for request $(66 \%$ vs $54 \%$; $P<.01)$, history of AMI as reason for request (29\% vs $42 \% ; P<.0001)$, and patients revascularized during follow-up (17\% vs $44 \%$; $P<.05)$. Table 1 contains the exercise data for patients with and without events. Of the 167 cardiovascular events, 120 occurred before any revascularization procedure was done and were used to estimate event-free survival by Kaplan-Meier and to construct survival curves. The causes of these 120 hard events were nonfatal AMI in 45 patients (38\%) and death in $75(62 \%)$. The causes of cardiovascular death were proven fatal AMI in 6, fatal deterioration of heart failure in 8 , sudden death in 6 , stroke in 6, and gangrene in 2. Out-of-hospital cardiovascular death was considered to have occurred in 39 patients after excluding other causes of noncardiovascular death from the death certificates. Heart transplantation in 4 patients and first discharge of defibrillator in another 4, were also considered hard events. The EE was positive in 89 of the 120 patients with events $(74 \%)$, in $24(20 \%)$ of the patients with necrosis, in $29(20 \%)$ of those with ischemia, in $33(28 \%)$ of those with remote ischemia, and in $3(3 \%)$ patients with ischemia and necrosis in the same territory. Multi-territory disease was detected in 59 of these patients (49\%). 
Table 1. Exercise Echocardiography and Echocardiographic data in Patients With and Without Hard Cardiovascular Events in the Follow-up*

\begin{tabular}{|c|c|c|c|}
\hline & Patients Without Events $(\mathrm{n}=2269)$ & Patients With Events (n=167) & $P$ \\
\hline Baseline HR, bpm & $79 \pm 14$ & $80 \pm 13$ & NS \\
\hline Baseline SBP, mm Hg & $138 \pm 19$ & $135 \pm 18$ & NS \\
\hline Maximum SBP, mm Hg & $174 \pm 29$ & $163 \pm 31$ & $<.0001$ \\
\hline Change in SBP, $\mathrm{mm} \mathrm{Hg}$ & $36 \pm 24$ & $28 \pm 23$ & $<.0001$ \\
\hline Theoretical maximum HR, \% & $0.92 \pm 0.12$ & $0.87 \pm 0.13$ & $<.0001$ \\
\hline Angina during test & $307(14 \%)$ & $34(20 \%)$ & .02 \\
\hline \multicolumn{4}{|l|}{ ECG } \\
\hline Positive & $357(16 \%)$ & $41(25 \%)$ & .005 \\
\hline Negative & $1217(53 \%)$ & $50(30 \%)$ & $<.0001$ \\
\hline Abnormal EE & $1069(47 \%)$ & $134(80 \%)$ & $<.0001$ \\
\hline \multicolumn{4}{|l|}{ EE response } \\
\hline Normal & $1200(53 \%)$ & $33(20 \%)$ & $<.0001$ \\
\hline Ischemia & $491(22 \%)$ & $56(34 \%)$ & $<.001$ \\
\hline Necrosis & $253(11 \%)$ & $29(17 \%)$ & .03 \\
\hline Remote ischemia & $239(11 \%)$ & $45(27 \%)$ & $<.0001$ \\
\hline Ischemia + necrosis in the same territory & $86(4 \%)$ & $4(2 \%)$ & NS \\
\hline Baseline RWM & $1.15 \pm 0.29$ & $1.38 \pm 0.42$ & $<.0001$ \\
\hline Peak RWM & $1.27 \pm 0.37$ & $1.62 \pm 0.46$ & $<.0001$ \\
\hline$\Delta$ of RWM & $0.12 \pm 0.23$ & $0.24 \pm 0.30$ & $<.0001$ \\
\hline
\end{tabular}

* AMI indicates acute myocardial infarction; ECG, electrocardiogram; EE, exercise echocardiography; EF, ejection fraction; HR, heart rate; METs, metabolic equivalents; NS, nonsignificant; RWM, regional wall motion; SBP, systolic blood pressure

Clinical, Stress Test, and Resting and Exercise Echocardiography Variables for Prediction of Cardiovascular Events

Table 2 shows the clinical, stress test, and echocardiography variables associated with the risk of cardiovascular events. Event-free survival and number of events in patients with normal EE versus those with involvement of 1, 2, and 3 territories are shown in Figure 1. Figure 2 shows event-free survival and number of events in patients with normal EE versus patients with EE who had necrosis, ischemia, or remote ischemia and Figure 3 indicates event-free survival according to RWM during exercise. 
Table 2. Risk of Hard Cardiovascular Events (Cardiovascular Death and Nonfatal Infarction) in Univariate Analysis of Clinical Variables, Stress Test, and Exercise Echocardiography*

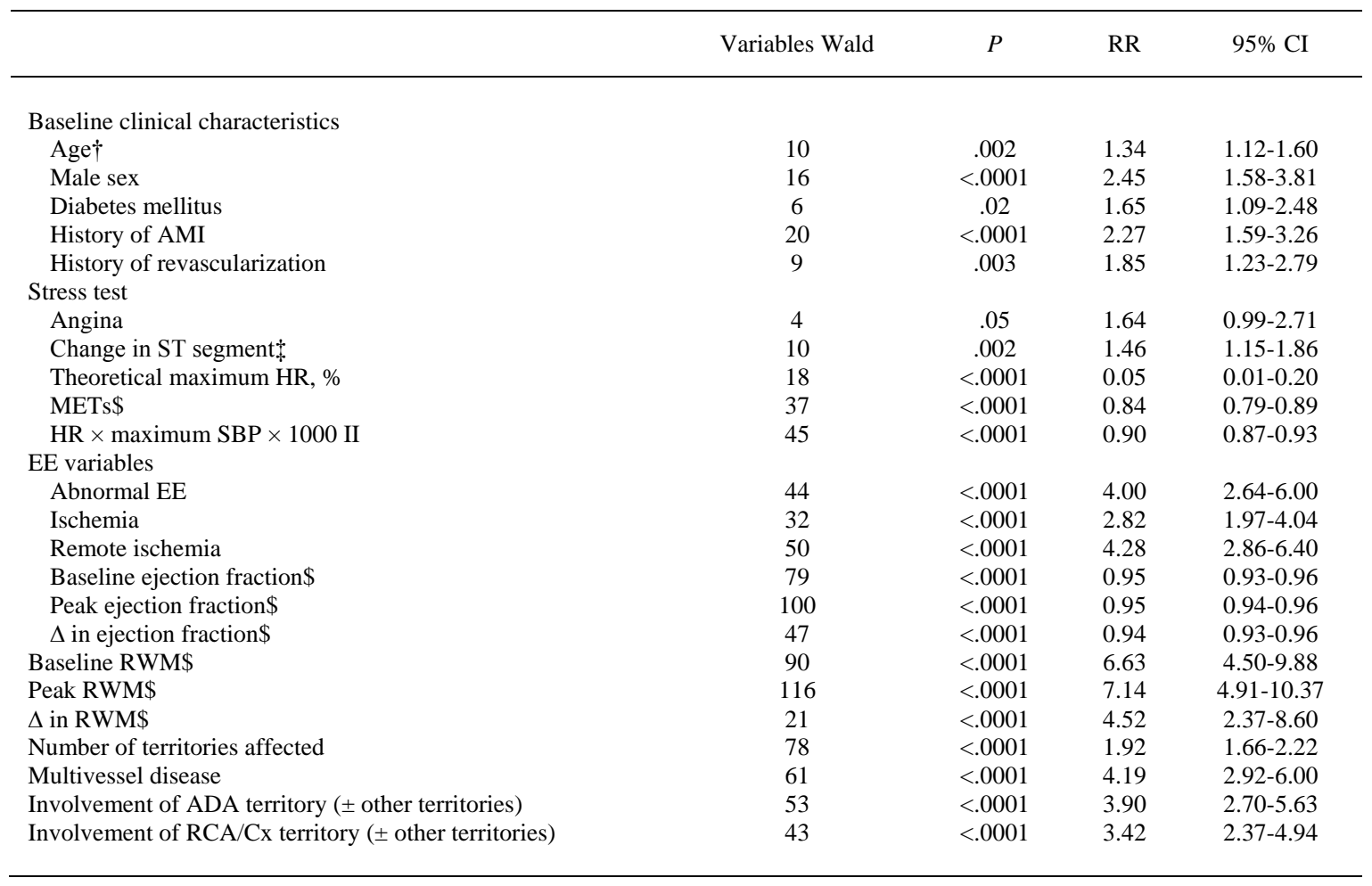

*AMI indicates acute myocardial infarction; CI, confidence interval; Cx, circumflex artery; EE, exercise echocardiography; HR, heart rate; LAD, left anterior descending artery; METs, metabolic equivalents; RCA, right coronary artery; RR, risk relative; RWM, regional wall motion; SBP, systolic blood pressure.

$\dagger$ According to decade.

$\$$ According to $\mathrm{mm}$ of change.

\$According to $1 \mathrm{U}$.

IIAccording to $1000 \mathrm{U}$

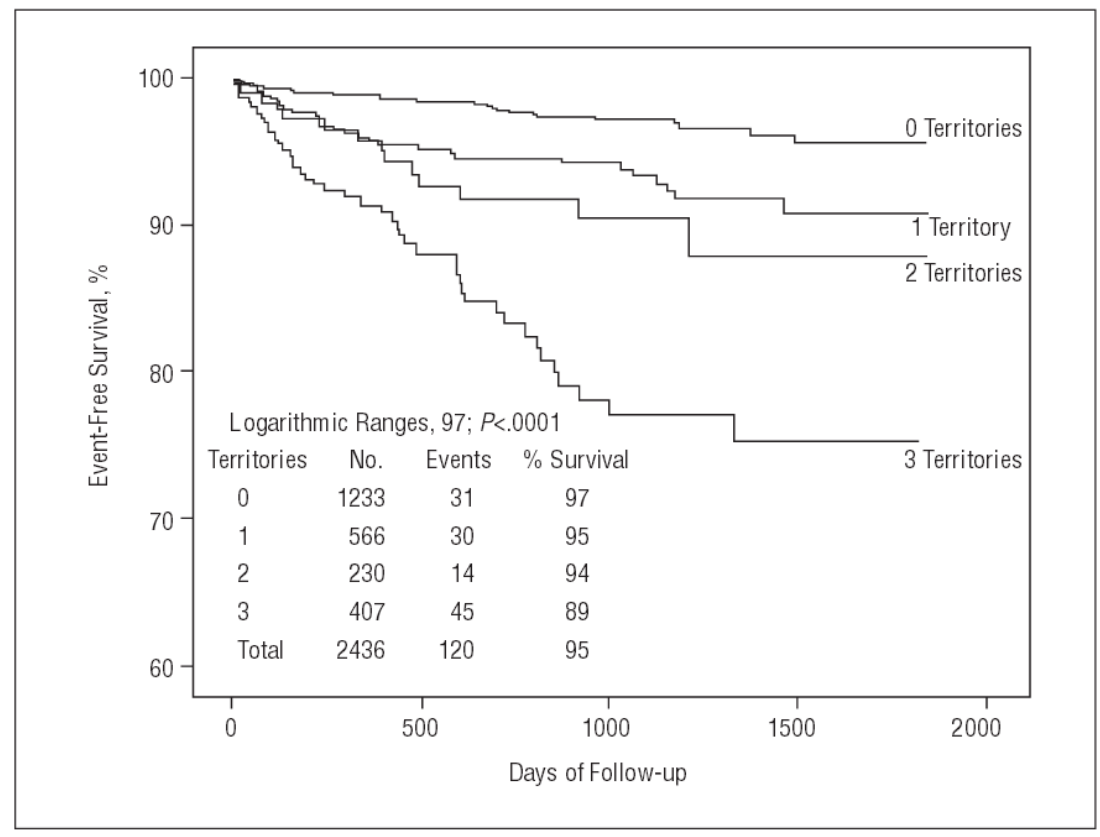

Figure 1. Kaplan-Meier survival curves and number of events in patients with involvement of $0,1,2$, and 3 territories on exercise echocardiography. 0 versus 1 territory, $P<.001$; 0 versus 2 and 3 territories, $P<.00001$; 1 versus 2 territories, $P=$ NS; 1 versus 3 territories, $P<.00001 ; 2$ versus 3 territories, $P<.01$ 


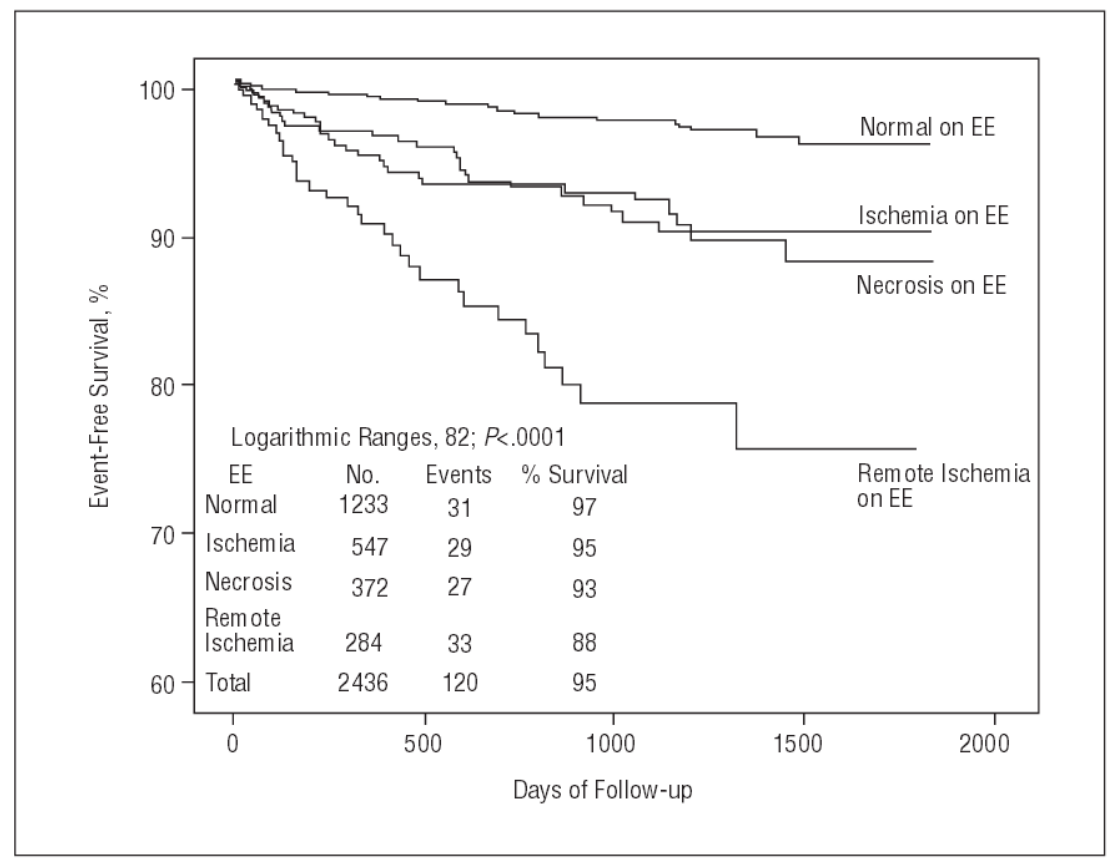

Figure 2. Kaplan-Meier survival curves and number of events in patients with normal results on exercise echocardiography, compared to patients with evidence of ischemia, necrosis, and remote ischemia. The necrosis subgroup includes patients with only necrosis in at least 1 territory, as well as patients with necrosis and associated ischemia in the same territory. Normal on EE versus other type of response, $P<.0001$; necrosis on EE versus ischemia on EE, $P=\mathrm{NS}$; necrosis on EE versus remote ischemia on EE, $P$ $<.001$; ischemia on EE versus remote ischemia on EE, $P<.001$. EE indicates exercise echocardiography.

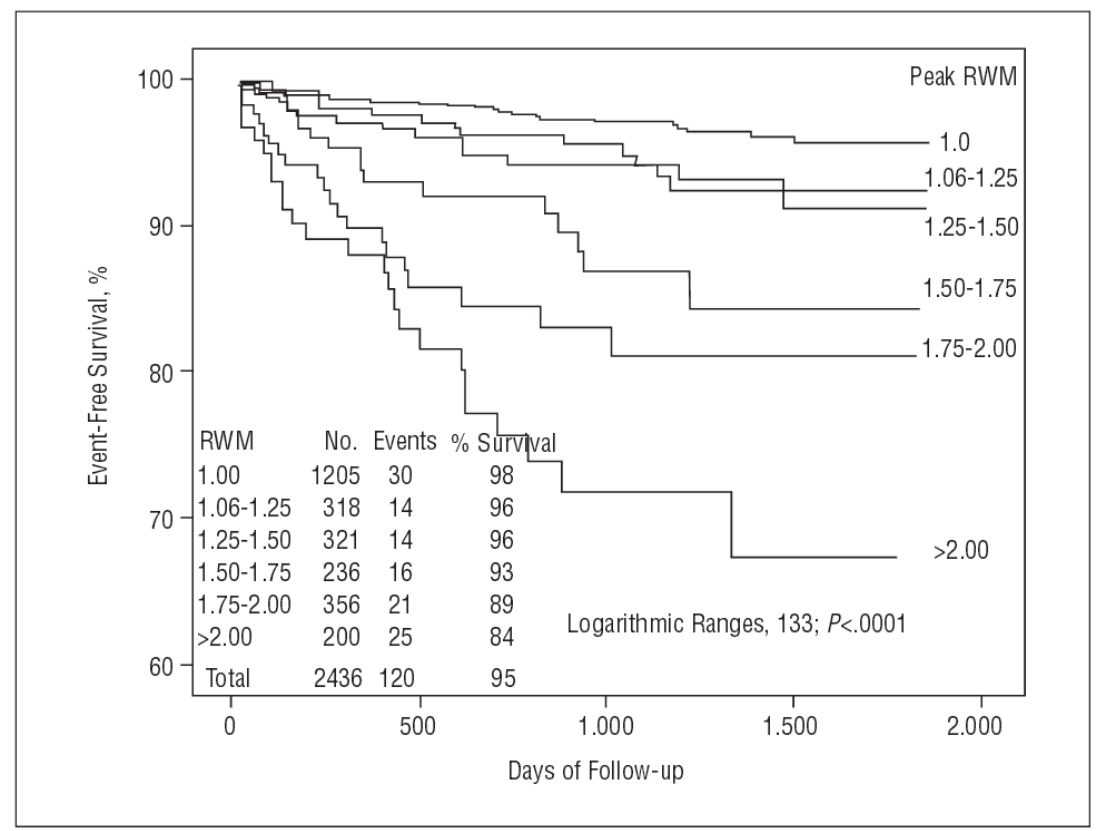

Figure3. Kaplan-Meier survival curves and number of events according to regional wall motion during exercise. 1.00 versus 1.06 $1.25, P<.05 ; 1.00$ versus $1.25-1.50,1.50-1.75,1.75-2.00$, and $>2.00, P<.00001 ; 1.06-1.25$ versus $1.25-1.50, P=\mathrm{NS} ; 1.06-1.25$ versus $1.50-1.75, P<.05 ; 1.06-1.25$ versus $1.75-2.00, P<.001 ; 1.06-1.25$ versus $>2.00, P<.00001 ; 1.25-1.50$ versus $1.50-1.75, P$ $=\mathrm{NS} ; 1.25-1.50$ versus $1.50-1.75, P<.001 ; 1.25-1.50$ versus $>2.00, P<.00001 ; 1.50-1.75$ versus $1.75-2.00, P=\mathrm{NS} ; 1.50-1.75$ versus $>2.00, P<.05 ; 1.75-2.00$ versus $>2.00, P=\mathrm{NS}$ 


\section{Predictors of Cardiovascular Death and AMI by Multivariate Analysis}

Table 3 contains the result of the four steps of the incremental model, including independent predictors for each step. In the final model, the independent predictors of hard cardiovascular events were: male sex, METs achieved, heart rate $\times$ maximum blood pressure, baseline RWM, and number of territories affected at exercise peak. The independent predictors of cardiovascular death were METs achieved (relative risk $[\mathrm{RR}]=0.88 ; 95 \% \mathrm{CI}, 0.80-0.96 ; P=.004)$, heart rate $\times$ blood pressure $(\mathrm{RR}=0.93$; 95\% CI, 0.89-0.98; $P=.003)$, baseline RWM (RR=3.8; 95\% CI, 2.1-7.0; $P<.0001)$, and number of territories affected in the exercise peak $(\mathrm{RR}=1.5 ; 95 \% \mathrm{CI}, 1.1-1.7 ; P=.015)$, but not sex $\left(\chi^{2}\right.$ of the final model $=169$; added value of exercise echocardiograph; $\mathrm{P}=.015$ ).

Table 3. Multivariate Analysis of: a) Clinical; b) Clinical and Stress Test; c) Clinical, Stress Test, and Resting Echocardiography; and d) Clinical, Stress Test, Resting Echocardiography, and Exercise Echocardiography Variables for Prediction of Events in 2436 Patients*

\begin{tabular}{|c|c|c|c|c|c|c|c|c|}
\hline \multirow[b]{2}{*}{ Variables } & \multicolumn{2}{|c|}{ Clinical Model } & \multicolumn{2}{|c|}{ Clinical Model + ST } & \multicolumn{2}{|c|}{$\begin{array}{c}\text { Clinical Model + ST + } \\
\text { Baseline Echo }\end{array}$} & \multicolumn{2}{|c|}{$\begin{array}{c}\text { Clinical Model }+\mathrm{ST}+ \\
\text { Baseline Echo }+ \text { Exercise } \\
\text { Echo }\end{array}$} \\
\hline & RR $(95 \% \mathrm{CI})$ & $P$ & $\mathrm{RR}(95 \% \mathrm{CI})$ & $P$ & $\mathrm{RR}(95 \% \mathrm{CI})$ & $P$ & $\mathrm{RR}(95 \% \mathrm{CI})$ & $P$ \\
\hline Age $\dagger$ & $1.4(1.2-1.7)$ & $<.0001$ & $1.0(0.9-1.3)$ & .6 & $1.0(0.9-1.3)$ & .7 & $1.0(0.9-1.3)$ & .7 \\
\hline Male & $2.2(1.4-3.5)$ & .001 & $2.4(1.5-3.9)$ & $<.0001$ & $2.0(1.2-3.2)$ & .004 & $1.7(1.1-2.8)$ & .02 \\
\hline History of AMI & $1.9(1.3-2.8)$ & $<.001$ & $1.7(1.1-2.4)$ & .008 & $1.3(0.9-1.9)$ & .2 & $1.2(0.8-1.7)$ & .4 \\
\hline METs $\ddagger$ & & & $0.87(0.82-0.93)$ & $<.0001$ & $0.90(0.84-0.97)$ & .003 & $0.92(0.86-0.98)$ & .01 \\
\hline $\mathrm{HR} \times \mathrm{SBP} \times 1000 \$$ & & & $0.94(0.90-0.97)$ & $<.0001$ & $0.94(0.91-0.98)$ & .002 & $0.4(0.91-0.98)$ & .002 \\
\hline Baseline RWM & & & & & $3.7(2.4-5.8)$ & $<.0001$ & $2.5(1.5-4.1)$ & $<.0001$ \\
\hline $\begin{array}{l}\text { No. territories affected } \\
\text { in EE }\end{array}$ & & & & & & & $1.4(1.2-1.7)$ & $<.0001$ \\
\hline Global $\chi^{2}$ & 43 & & 99 & & 155 & & 170 & \\
\hline Incremental P & & & $<.0001$ & & $<.0001$ & & & $<.0001$ \\
\hline
\end{tabular}

*AMI indicates acute myocardial infarction; CI, confidence interval; EE, exercise echocardiography; Echo, echocardiography; HR, heart rate; METs, metabolic equivalents; RWM, regional wall motion; SBP, systolic blood pressure; ST, stress test; RR, relative risk $\uparrow$ According to decade.

†According to $1 \mathrm{U}$

\$According to $1000 \mathrm{U}$

\section{Predictors of Events in Patients With History of AMI}

Among the 741 patients with a history of AMI, there were 53 events (7\%; 22 nonfatal infarctions, and 31 deaths of cardiovascular origin). The EE was abnormal in $93 \%$ of the patients with events, with necrosis in $19(36 \%)$, ischemia in $10(19 \%)$, remote ischemia in $18(34 \%)$, and ischemia and necrosis in the same territory in $2(4 \%)$. Exercise echocardiography indicated multivessel disease in $29(55 \%)$. The independent predictive variables of hard events in the final model of patients with AMI were METs achieved, product of heart rate $\times$ blood pressure and peak EF (Table 4). 
Table 4. Multivariate Analysis of: a) Clinical; b) Clinical and Stress Test; c) Clinical, Stress Test, and Resting Echocardiography; and d) Clinical, Stress Test, Resting Echocardiography, and Exercise Echocardiography Variables for Prediction of Events in 741 Patients with a history of Acute Myocardial Iinfarction*

\begin{tabular}{|c|c|c|c|c|c|c|c|c|}
\hline Variables & \multicolumn{2}{|c|}{ Clinical Model } & \multicolumn{2}{|c|}{ Clinical Model + ST } & \multicolumn{2}{|c|}{$\begin{array}{l}\text { Clinical Model + ST + } \\
\text { Baseline echo }\end{array}$} & \multicolumn{2}{|c|}{$\begin{array}{c}\text { Clinical Model }+\mathrm{ST}+ \\
\text { Baseline Echo }+ \text { Exercise } \\
\text { Echo }\end{array}$} \\
\hline Age $\dagger$ & $1.9(1.4-2.6)$ & $<.0001$ & $1.3(0.9-1.8)$ & .1 & $1.3(0.9-1.8)$ & .2 & $1.2(0.9-1.7)$ & .2 \\
\hline METs + & & & $0.86(0.78-0.95)$ & $\begin{array}{l}.0 \\
02\end{array}$ & $0.88(0.80-0.98)$ & .02 & $0.89(0.81-1.0)$ & .04 \\
\hline $\mathrm{HR} \times \mathrm{SBP} \times 1000 \$$ & & & $0.93(0.88-0.99)$ & $\begin{array}{l}.0 \\
2\end{array}$ & $0.94(0.88-1.00)$ & .04 & $0.93(0.88-0.94)$ & .03 \\
\hline Baseline EF & & & & & $0.96(0.94-0.99)$ & .004 & $1.00(0.96-1.04)$ & 1 \\
\hline Peak EF! & & & & & & & $0.96(0.94-0.99)$ & .02 \\
\hline Global $\chi^{2}$ & 17 & & 45 & & 58 & & 62 & \\
\hline Incremental $P$ & & & $<.0001$ & & .005 & & .02 & \\
\hline
\end{tabular}

*CI indicates confidence interval; Echo, echocardiography; EE, exercise echocardiography; EF, ejection fraction; HR, heart rate; METs, metabolic equivalents RR: risk relative; SBP, systolic blood pressure; ST, stress test $\dagger$ According to decade.

†According to $1 \mathrm{U}$.

\$According to $1000 \mathrm{U}$

\section{Between-Observer Variability in Ejection Fraction Calculation}

The between-observer variation was $9 \% \pm 9 \%$ for baseline EF calculation and $10 \% \pm 10 \%$ for peak EF calculation.

\section{Discussion}

The most significant findings of this study were:

a) EE supplements the clinical, stress test, and baseline echocardiography variables among a population with moderate-to-high pretest prevalence of CAD; b) a response of remote ischemia is significantly associated with poor prognosis, when compared to other types of response; and c) the added value of resting and exercise echocardiography is also observed in the subgroup of patients with a history of AMI.

\section{Prognostic Value of Exercise Echocardiography}

The incremental value of EE we found in our study has been previously demonstrated in recent studies, ${ }^{1-10}$ although most were performed at the same center. However, the present study is the first to investigate this aspect in Spain and the first to use echocardiography during the exercise peak, instead of post-exercise or pharmacological echocardiography. We should mention that EE in general is a widely used technique in our setting, ${ }^{21}$ and that $\mathrm{EE}$ at the exercise peak in particular is commonly used at various centers in Spain. The patients with three coronary territories affected during the exercise peak presented a high risk of events (11\% of events at 2 years), when compared with those who had fewer territories affected. Nevertheless, there were no differences between 1 and 2 territories (5\% vs $6 \%$ of events). Involvement of only 1 territory or even of 2 territories, if dependent on the right coronary or circumflex arteries, was not associated with significant risk in the univariate analysis.

\section{Type of Response}

The risk associated with the response of remote ischemia of a necrosis (12\% events at 2 years) was significantly higher than the risk associated with other types of response. The risk associated with necrosis was found to be equal to the risk associated with ischemia. More patients with ischemia than with necrosis were excluded due to revascularizations, however, which may explain this lack of difference. Lastly, patients with RWM during the exercise peak $>1.5$ had a high risk of presenting events, with $10.5 \%$ of events in patients with RWM of $1.75-2.00$ and $16 \%$ in those with RWM>2.0. 


\section{Exercise Echocardiography in Patients With a History of AMI}

Since EE is particularly indicated in patients with a history of AMI due to the baseline alterations of repolarization that prevent an assessment of the $\mathrm{ECG},{ }^{22}$ we were interested in analyzing these patients separately. In these patients we also found that an exercise imaging variable added significant value to the model above the resting echocardiography variables, which were not significant in the final model. However, the EE variable that enhanced the model was peak EF rather than RWM or ischemia, possibly reflecting the difficulty encountered for detecting pre-infarction ischemic areas and the prognostic value of the amount of necrotic myocardium with no contractility reserve.

\section{Limitations}

As mentioned above, EE was performed at the exercise peak instead of post-exercise since imaging at the exercise peak has been shown to have greater sensitivity. ${ }^{11,12,23}$ Nevertheless, the superiority of the echocardiography variables in the exercise peak over the clinical, ECG, and resting echocardiography variables we found in this study could be diminished if the EE is performed after exercise.

Since the EE results were used by the attending physician, the apparent prognostic information could be reduced, since most patients with severely positive tests who were revascularized might have presented serious events if they had not undergone revascularization.

The definition of nonfatal AMI was based on criteria from the pre-troponin era for most patients and therefore, although we have records on hospitalization for unstable angina, AMI was only considered to exist when it was specifically indicated in the medical reports. As a result, we are probably referring to infarctions of a certain entity in which, if the current, more sensitive criteria had been used, the number of events would be greater at the expense of nonfatal AMI. Nevertheless, we feel this does not diminish the value of our study, since EE continued to be associated with cardiovascular mortality.

Approximately $40 \%$ of the EEs were performed with fundamental imaging. The technology has dramatically improved since that time through the development of harmonic imaging and continuous image acquisition, which could result in greater sensitivity of the technique. Unfortunately, this is a common problem that affects continuous longitudinal studies conducted in this field.

\section{Clinical Implications}

Risk measurement with EE is superior to measurement with clinical, stress test, and baseline echocardiography variables. Patients who present involvement of 3 territories, remote ischemia, and peak RWM $>1.75$ on EE are at high risk for hard cardiovascular events.

\section{References}

1. AM Arruda-Olson, EM Juracan, DW Mahoney, RB McCully, VL Roger, PA Pellikka. Prognostic value of exercise echocardiography in 5,798 patients: is there a gender difference?. J Am Coll Cardiol., 39 (2002), pp. 625-631.

2. AM Arruda, MK Das, VL Roger, KW Klarich, DW Mahoney, PA Pellikka. Prognostic value of exercise echocardiography in 2,632 patients $\geq 65$ years of age. J Am Coll Cardiol., 37 (2001), pp. 1036-1041.

3. A Elhendy, DW Mahoney, KN Burger, RB McCully, PA Pellikka. Prognostic value of exercise echocardiography in patients with classic angina pectoris. Am J Cardiol., 94 (2004), pp. 559-563.

4. RB McCully, VL Roger, DW Mahoney, KN Burger, RL Click, JB Seward, et al. Outcome after abnormal exercise echocardiography for patients with good exercise capacity: prognostic importance of the extent and severity of exercise-related left ventricular dysfunction. J Am Coll Cardiol., 39 (2002), pp. 1345-1352.

5. A Elhendy, DW Mahoney, BK Khandheria, TE Paterick, KN Burger, PA Pellikka. Prognostic significance of the location of wall motion abnormalities during exercise echocardiography. J Am Coll Cardiol., 40 (2002), pp. $1623-1629$.

6. A Elhendy, DW Mahoney, BK Khandheria, K Burger, PA Pellikka. Prognostic significance of impairment of heart rate response to exercise: impact of left ventricular function and myocardial ischemia. J Am Coll Cardiol., 42 (2003), pp. 823-830.

7. RB McCully, VL Roger, SR Ommen, DW Mahoney, KN Burger, WK Freeman, et al. Outcomes of patients with reduced exercise capacity at time of exercise echocardiography. Mayo Clin Proc., 79 (2004), pp. 750-757.

8. S Bergeron, SR Ommen, KR Bailey, JK Oh, RB McCully, PA Pellikka. Exercise echocardiographic findings and outcome of patients referred for evaluation of dyspnea. J Am Coll Cardiol., 43 (2004), pp. 2242-2246.

9. A Elhendy, C Shub, RB McCully, DW Mahoney, KN Burger, PA Pellikka. Exercise echocardiography for the prognostic stratification of patients with low pretest probability of coronary artery disease. Am J Med., 111 (2001), pp. 18-23. 
10. TH Marwick, C Case, L Short, JD Thomas. Prediction of mortality in patients without angina: use of an exercise score and exercise echocardiography. Eur Heart J., 24 (2003), pp. 1223-1230.

11. J Peteiro, L Monserrat, R Pérez, E Vázquez, JM Vázquez, A Castro-Beiras. Accuracy of peak treadmill exercise echocardiography to detect multivessel coronary artery disease: comparison with post-exercise echocardiography Eur J Echocardiogr., 4 (2003), pp. 182-190.

12. J Peteiro, I Garrido, L Monserrat, G Aldama, R Calvino, A Castro-Beiras. Comparison of peak and postexercise treadmill echocardiography with the use of continuous harmonic imaging acquisition. J Am Soc Echocardiogr., 17 (2004), pp. 1044-1049.

13. PD Bourdillon, TM Broderik, SG Sawada, WJ Armstrong, T Ryan, JC Dillon, et al. Regional wall motion index for infarct and no-ninfart regions after reperfusion in acute myocardial infarction: comparison with global wall motion index. J Am Soc Echocardiogr., 9 (1989), pp. 398-407.

14. NB Schiller, PM Shan, M Crawford, A De Maria, R Devareaux, H Feigenbaum, et al. Recommendations for quantification of the left ventricle by two dimensional echocardiography. J Am Soc Echocardiogr., 2 (1989), pp. 358-367.

15. R Hoffmann, H Lethen, T Marwick, R Rambaldi, P Fioretti, A Pingitore, et al. Standardized guidelines for the interpretation of dobutamine echocardiography reduce interinstitutional variance in interpretation. Am J Cardiol., 82 (1998), pp. 1520-1524.

16. J Peteiro Vázquez, L Monserrat Iglesias, E Vázquez Rey, R Calviño Santos, JM Vázquez Rodríguez, R Fabregas Casal, et al. Ecocardiografía de ejercicio para diferenciar la miocardiopatía dilatada de la disfunción ventricular por cardiopatía isquémica. Rev Esp Cardiol., 56 (2003), pp. 57-64.

17. VL Roger, PA Pellikka, JK Oh, KR Bailey, AJ Tajik. Identification of multivessel disease by Exercise Echocardiography. J Am Coll Cardiol., 24 (1994), pp. 109-114.

18. MA Quiñones, MS Verani, RM Haichin, JJ Mahmariam, J Suárez, WA Zoghbi. Exercise echocardiography versus $201 \mathrm{Tl}$ singlephoton emission computed tomography in evaluation of coronary artery disease. Analysis of 292 patients. Circulation, 85 (1992), pp. 1026-1031.

19. TH Ryan, CHG Vasey, F Presti Ch, JA O'Donnell, H Feigenbaum, WF Armstrong. Exercise echocardiography: detection of coronary artery disease in patients with normal left ventricular wall motion at rest. J Am Coll Cardiol., 11 (1988), pp. 993-999.

20. RB Stamm, BA Carabello, DL Mayers, RP Martin. Two-dimensional echocardiographic measurement of left ventricular ejection fraction: prospective analysis of what constitutes and adequate determination. Am Heart J., 104 (1982), pp. 136-144.

21. MA Rodríguez García, I Iglesias-Garriz, F Corral Fernández, C Garrote Coloma, N Alonso-Orcajo, L Branco, et al. Evaluación de la seguridad de la ecocardiografía de estrés en España y Portugal. Rev Esp Cardiol., 54 (2001), pp. 941-948.

22. MD Cheitlin, WF Armstrong, GP Aurigemma, GA Beller, FZ Bierman, JL Davis, et al. ACC/AHA/ASE 2003 guideline update for the clinical application of echocardiography-summary article: a report of the American College of Cardiology/American Heart Association Task Force on Practice Guidelines (ACC/AHA/ASE Committee to Update the 1997 Guidelines for the Clinical Application of Echocardiography). J Am Coll Cardiol., 42 (2003), pp. 954-970.

23. SM Badruddin, A Ahmad, J Mickelson, J Abukhalil, WL Winters, SF Nagueh, et al. Supine bicycle versus posttreadmill exercise echocardiography in the detection of myocardial ischemia: a randomized single-blind crossover trial. J Am Coll Cardiol., 33 (1999), pp. 1485-1490. 